УДК 8

DOI $10.21661 / \mathrm{r}-462476$

\title{
C.C. Кабанова
}

\section{ОСОБЕННОСТИ КОММУНИКАЦИИ ИСПАНСКОЙ И АНГЛИЙСКОЙ КУЛЬТУР}

Аннотация: в работе раскрывается вопрос особенностей коммуникации испанской и английской культур на примере сравнительно-сопоставительного анализа вербального и невербального языкового поведения, рассматриваются культурные ценности, их отражение в языке. В основе исследования заложены исторический, географический и климатический компоненты, восприятие времени, которые обуславливают национально-культурную специфику выражения и обмена мыслей, помогают предотвратить недопонимания в процессе акта коммуникации.

Ключевье слова: коммуникация, специфика, ценности, действительность, время, язык.

\section{S.S. Kabanova \\ COMMUNICATION PECULIARITIES IN SPANISH AND ENGLISH CULTURES}

Abstract: the article reveals the question of communication peculiarities in Spanish and English cultures using an example of comparison and collation of verbal and nonverbal linguistic behavior; describes cultural values and their expression in the language. The research is based on historic, geographic and climate components and perception of time, that are responsible for national and cultural specificity of expression and exchange of thoughts and help to avoid misunderstanding in the process of communication.

Keywords: communication, peculiarity, values, reality, time, language. 
Межкультурная коммуникация - связь между представителями разных культур, контакты, их формы между индивидами. На настоящий момент, в рамках прогрессирующих контактов с представителями других культур, представляет интерес изучение специфики коммуникации в процессе выражения и интерпретации языковых действий коммуникантов: языковые особенности, восприятие времени и пространства, традиции, ритуалы, этикет для избежания коммуникативного конфликта в бытовой, социальной, экономической и политической сферах. Согласно определению Светланы Георгиевны Тер-Минасовой: «коммуникация позволяет участникам выражать некоторую внешнюю по отношению к самим участникам информацию, внутреннее эмоциональное состояние, а также статусные роли, в которых они пребывают друг относительно друга», [1]. На настоящий момент, самыми востребованными и распространёнными в России языками являются английский и испанский, поэтому они рассматриваются с позиции сравнительно-сопоставительного анализа национально-культурных особенностей коммуникации. С позиции Испании, её «геополитическое положение, физико-географические условия и миграционные процессы, борьба населения за освобождение от арабов и мавров, колонизации Америки, и распространения на Иберийском полуострове христианской (католической) религии, оказали влияние на формирование и закрепление языковых особенностей в национальной психологии испанцев» [2]. История английского языка связана с историей страны и представлена тремя периодами: 1) древнеанглийский (Old English) c 450 г. по 1066 г. (германские племена саксов, ютов, англов и фризов, которые проникли на территорию Британии); 2) среднеанглийский (Middle English) c 1066 по 1500 г. (завоевание Британии Францией. эпоха трёх языков: французского (язык аристократии), латыни (язык науки), английского (язык низших слоёв общества); 3) новоанглийский период (Modern English) с 1500 г. по наши дни (время географических открытий, присоединение новых земель к британской империи). 
Как следствие, для испанцев характерны такие черты как экспрессивность, открытость. С точки зрения аксиологии - основными ценностями будут социальные: честь, патриотизм, семья. Как следствие, в деловом плане испанцев интересуют партнёры как личности, больше, чем предмет торгово-рыночных отношений, поэтому в процессе коммуникации «неприемлемы холодность и диктат времени» [Там же]. С позиции проксемики, данной культуре присущи интимная и персональная межсубъектные зоны, и испанцы относятся к контактному типу, несмотря на то, что в некоторых регионах Испании до сих пор используются социально-дистантные способы обращения - «señor», «señora», «señorita», местоимённые формы «Usted» / Вы - ед. ч. «Ustedes» / Вы - мн. ч., которые являются показателями социально-возрастных признаков. Налицо тенденция к неформальному общению: студент к преподавателю может обратиться к на «ты» (tú). Тем не менее, для старшего поколения, такая демонстрация взаимоотношений является показателем фамильярности, нарушения этикета [3].

Восприятие времени оказывает влияние на межкультурную коммуникацию. Гонсалес и Зимбардо в работах о восприятии времени отмечают: «Ничто не влияет на то, как мы думаем, и на то, как взаимодействуют между собой представители разных культур, так сильно, как разный подход к восприятию времени, то есть то, как мы делим время на прошлое, настоящее и будущее» [4, с. 227]. Испания - полихронный тип, пунктуальность не играет роли, что выражается лексемой «mañana» / «утро», «завтра». В противоположность Англия - монохронный тип, преобладание в речи настоящего длительного времени (Present Continuous), ориентированность на прошлое, использование непрямого стиля общения. Согласно исследованию, Л. Броснахана, англичанам свойствена социальная и публичная дистанция (sense of privacy) - в противоположность испанской культуре, соответственно англичане принадлежат дистантному типу, что проявляется в фразеологизмах, пословицах, поговорках «keep distance», «stay clear of smb.» / «сохранять дистанцию» [5, с. 97]. Ценностями англичан являются: личное про- 
странство, независимость, понятие материального благосостояния играет огромную роль «а man of large fortune» / «человек с большим состоянием» [1, с. 130]. В английском языке, такие обращения как «Sir» / «Madam» / «Mr.» / «Miss» / «Mrs.», постепенно уходят в прошлое, как и в испанском языке, указывают на сокращение дистанции между младшими и старшими индивидами, симметричность отношений индивидов в процессе коммуникации.

Вербальные и паравербальные средства общения дополняют собой коммуникацию. При помощи языка, испанцы красноречиво и ярко проявляют впечатления от окружающего мира. Для выражения мыслей испанцы используют во всей полноте тембр, интонацию, быстрый темп речи, перебивают друг друга (не является нарушением этикета и норм поведения), активно жестикулируют, употребляют разнообразие уменьшительно-ласкательных суффиксов (для м. рода: ito, -cito, -ecito, -ececito; -illo, -cillo, -ecillo, -ececillo; для ж. рода: те же суффиксы, но вместо конечного -о ставится -a, -ita,-cita; -illa, -ecilla и т. д.), экспрессивные прилагательных, гиперболы, сравнения «más flaco que un fideo» / «очень худой, тоньше вермишели» [6, с.93], которые помогают испанцам передать гамму чувств и отношения к собеседнику (выражение убеждённости в своей правоте подаётся в энергичной эмоциональной форме: «Nos consta que ustedes no están informados de lo que viene sucediendo» / «Нам кажется, что Вас не проинформировали о происходящем»; проявление уважения к клиенту, отсутствие резкости суждения, категоричности высказываний: «Confíamos en que tal eventualidad no se produzса» / «Надеемся, что подобная ситуаџия не произойдет», «Quiere ипа taza de café? - Si, por favor» / «Не желаете выпить чамечку кофе? - Да, спасибо за предложение»). Относительно паравербальных средств коммуникации англичан, представители этой культуры предпочитают говорить тихим голосом, в среднем темпе (быстрее, чем финны, но медленнее чем французы), не перебивая друг друга - «turn-taking» / «поочередность реплик»; не допускают длинных пауз, нетерпимы к молчанию (средством заполнения пауз в английской коммуникации является «small talk» [7].

4 www.interactive-plus.ru

Содержимое доступно по лицензии Creative Commons Attribution 4.0 license (CC-BY 4.0) 
Сталкиваясь с разнообразием особенностей представителей пиренейской культуры, мы ощущаем специфику языка, обусловленную грамматикой, лексикой, семантикой, речевым поведением, которое усложняет задачи межкультурного общения. Представители английской и испанской культур не всегда могут добиться полного взаимопонимания в ходе коммуникации в силу социокультурных особенностей, коммуникативного поведения, способов невербального, паравербального и вербального выражения сообщения, различий в картинах мира (научных, языковых и т. д.), разного исторического опыта, ментальности, ценностей, своеобразия географического положения и климатических условий. Как следствие, необходимо отслеживать и выявлять специфику коммуникации внутри культур, на примере английской и испанской, для своевременного предотвращения недопонимания, конфликтных, курьёзных ситуаций.

\section{Список литературы}

1. Тер-Минасова С.Г. Язык и межкультурная коммуникация. - М., 2000 [Электронный ресурс]. - Режим доступа: http://files.school-collection.edu.ru (дата обращения: 15.04.2017).

2. Ларина М.В. Особенности деловой коммуникации в испанской культуре [Электронный ресурс]. - Режим доступа: http://www.vestnik-kafu.info (дата обращения: 15.04.2017).

3. Деловая культура и психология общения [Электронный ресурс]. - Режим доступа: http://syntone.ru (дата обращения: 28.05.2017).

4. Guerrero, L.K., Devito J.A.,\& Hecht M.L. The Nonverbal Communication Reader: Classic and contemporary readings (2nd ed.). Long Grove, IL: Waveland Press, Inc., 1999.

5. Ларина Т.В. Англичане и русские: Язык и культура, коммуникация. - М.: Языки славянских культур, 2013. - 360 с. 
6. Diccionario Fraseológico Documentado del Español Actual. Locuciones y modismos / M. Seco, O. Andrés, G. Ramos; dir. por M. Seco. - 2a ed. - Madrid: Aguilar lexicografía, 2007.

7. Комарова Е.А. Особенности коммуникации русских и англичан [Электронный ресурс]. - Режим доступа: http://nsportal.ru (дата обращения: 28.05.2017)

Кабанова Светлана Сергеевна - магистрант АНО ВО «Международный институт менеджмента ЛИНК», Россия, г. Жуковский.

Kabanova Svetlana Sergeevna - graduate student at ANCO of HE "International Institute of Management LINK”, Russia, Zhukovsky city. 